\title{
HIV in Saskatchewan merits urgent response
}

S askatchewan's high HIV rates are a public health emergency and must be treated as one, say health professionals. For the past decade, the province has reported transmission rates double the Canadian average, peaking at over 19 cases per 100000 people in 2009.

The outbreak is mostly driven by injection drug use and has hit indigenous communities hardest. According to Health Canada, the rate of new infections on reserves was 64 per 100000 people at last count. That is nearly 11 times the national average of 5.9 per 100000 , and rivals nations like Nigeria and Rwanda.

These statistics likely underestimate the full scope of the crisis, says Dr. Ryan Meili, a family physician at a Saskatoon clinic. Although Saskatchewan now recommends routine screening for HIV, "there isn't a comprehensive strategy on reserves," says Meili. "We know that a couple [out of 80] reserves have done testing and found a large number of cases, and it's concerning what might be happening where there isn't testing."

There are stories of families sharing needles - grandmothers and mothers shooting up with children and cousins and of people dying of HIV on reserve without ever receiving a diagnosis.

Meili and others are advocating for a "plan that is proportional to the problem," he says. "There's been a response, but a slow response; it's been like the response to a chronic disease increase, not the response to an outbreak."

The rate of new infections rose steadily for five years before Saskatchewan issued an HIV strategy in 2010. Subsequently, 40 new testing sites opened and more than 1000 public education sessions took place across the province, among other projects.

According to Dr. Mona Loutfy, a Toronto infectious disease specialist who also practises in Saskatchewan, most of the actual implementation has fallen to regional health authorities, community organizations and even individuals.

"It's all grassroots," Loutfy explains. "It takes a nurse to say, 'I'm going to do

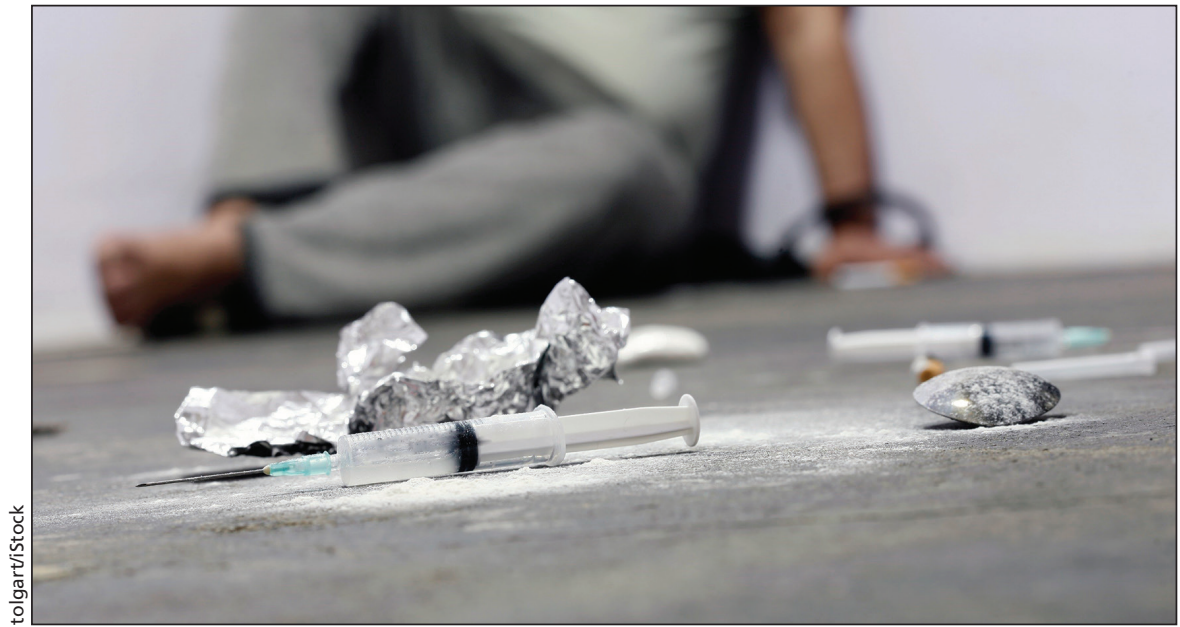

Saskatchewan has reported high HIV rates driven by injection drug use for 10 years now.

this testing program,' but there's no provincial public health mandate."

Dr. Denise Werker, deputy chief medical health officer for the province, admits that a bottom-up approach has resulted in patchwork progress. "Because of the resources that are available in larger cities, the initial work was most easily done in Regina and Saskatoon. In the rural and remote communities, a whole lot more needs to be done."

Since Saskatchewan's HIV strategy expired in 2014, "we are limited by what we can do within the construct of our current budget," adds Werker. The province still dedicates \$4 million a year to continue work started under the old strategy. According to a final evaluation released this month, it's still too early to report any "observable outcomes or impacts" of these efforts. No new plan or funds are expected for the time being. The federal government earmarks \$1.5 million a year for HIV/AIDS programming on Saskatchewan reserves. Health Canada typically doesn't develop or deliver interventions directly; instead, reserves can request money and technical support for programs of their own design. "They ask us for whatever amount and if we have it, we give it to them and it's up to them what they do with it," says Dr. Ibrahim Khan, Health Canada's regional medical health officer for Saskatchewan First
Nations. HIV programming varies widely from one reserve to the next; only 5 of 80 do point-of-care HIV testing.

\section{Indiana's success}

Meili and Loutfy argue that it borders on indifference to allow rates to remain so high for so long. They say Saskatchewan should follow the example of Indiana, which is curbing a similar spike of new HIV infections through a more intensive, emergency response.

Since December 2014, one county in Indiana has reported 170 HIV cases, up from a previous maximum of 5 per year. Most of the cases are among poor, rural African Americans, and health officials attribute the outbreak to an explosion of injection drug use.

"We saw very quickly this was going to require an all-hands-on-deck response," says Pam Pontones, an epidemiologist for the state department of health.

In February, Indiana called in an epidemiological "A team" from the Centers for Disease Control and Prevention to assist with "disease intervention specialists, contact tracing, epidemiology and medical perspectives on the ground," Pontones explains. Soon after, the state governor officially declared a public health emergency and, despite previously opposing needle exchange 
programs, authorized one in the county.

In the space of several months, Indiana has also opened 20 testing sites across the county and set up a "onestop shop" for various expedited services from across state agencies. These run the gamut "from health insurance enrolment, to birth certificate and ID cards, to mental health and addiction treatment services, so there are no barriers to medical care," says Pontones.

At last report, the number of new cases has dropped from a peak of 23 a week to a range of 0-3 a week, and the state has yet to spend all \$2.1 million it set aside for the response.

"All levels of government came in full force to put a lid on the Indiana outbreak, and we haven't seen the same kind of action in Saskatchewan yet, particularly from the federal government," says Meili.

Loutfy says jurisdictional squabbles remain a major barrier. "There's this back and forth, 'That should be a pro- vincial responsibility,' or 'That should be a federal responsibility,' and all you're left with is these vulnerable people caught in the middle who aren't getting adequate care."

She also cites racism as a factor. "There's quite a bit towards the Aboriginal community in Saskatchewan," Loutfy explains. "Without public sympathy, I'm not sure there's a lot of political interest."

But it's also possible that health officials are uncomfortable with the level of paternalism inherent in an emergency response, given the troubled relationship between indigenous Canadians and government.

"We just go with the willingness and readiness of each community," says Khan. "It doesn't entirely depend on us.... The whole partnership has to be ready. That's what we're aiming for, and that's what we're waiting for."

David Ironstand of Cote First Nation in southeastern Saskatchewan says that action is unlikely on some reserves where stigma and ignorance of HIV persist.

He avoided getting tested for years and when he finally learned that he was HIV positive, members of his family cut off contact. "We used to be a family that would always hold one another and kiss one another, but from then on they didn't do that with me."

The same attitudes and fears extend to some indigenous leaders, says Ironstand. "It's the ostrich thing; they're sticking their heads in the sand and hoping it will go away."

In August, Ironstand and others will walk more than 300 kilometres from Saskatoon to his reserve near Kamsack, visiting indigenous communities along the way to raise awareness of HIV. "This is my way of getting out there and giving it more of a voice," he says. — Lauren Vogel, CMAJ

CMAJ 2015. DOI:10.1503/cmaj.109-5105

\section{Surgical black box may sew up malpractice cases}

$\mathrm{W}$ hen an airplane crashes, investigators scramble to locate the black box so they can find out what was happening in the aircraft before the incident. An advance on that technology is now being tested at a Canadian hospital as a means of documenting what happens in an operating room. The question is how will that documentation be used.

Dr. Teodor Grantcharov, Canada Research Chair in Simulation and Surgical Safety at the University of Toronto has been researching the use of a surgical black box for the past year at St. Michael's Hospital in Toronto. The technology involves several cameras and microphones, along with sensors to document physiological data and key aspects of the environment, such as temperature. Postsurgery the data are assessed by a performance team.

"It allows us to objectively reconstruct what happens," says Grantcharov.

The intent of the new technology is to enhance health team performance, pinpoint errors and missteps (human and otherwise), and subsequently identify ways to prevent and address those issues. However, the data in an operating room black box could be used as evidence in medical malpractice suits unless precluded by legislation - in much the same way morbidity and mortality assessments made by hospitals and staff for the purpose of quality assurance and improvements are exempt from being used in court.

Grantcharov would like to see black box data exempted. "This should be protected and not used in court. It should be used to benefit the profession and the safety of patients. It would be wrong to fuel the litigation industry."

Data recorded by the black box system could well speak for patients unable to speak for themselves because they were under anaesthesia or unfamiliar with hospital procedures and protocol.

However, lawyer Ray Wagner, founder of "Wagners — A Serious Injury Law Firm in Halifax," says the data could also help surgeons who are being sued. "With the black box, critical procedures and techniques could be objectively assessed by peer surgeons when a poor outcome occurs. From the surgeon's point of view, the data would be confir- mation that all was done right but the poor outcome was beyond their control."

Good medical care includes clear communication and thorough documentation, according to the Canadian Medical Protective Association. Dr. Gordon Wallace, managing director of safe medical care, says "This same documentation is also important for demonstrating the quality of care provided if the care comes into question at a later date."

Wagner acknowledges the documentation of surgical procedures could add a layer of anxiety to the operating room team. "But," he points out, "it may eliminate the need for lengthy litigation when the record confirms or denies the accusations of malpractice."

At present, the use of black box technology at St. Michael's is in the research stage and all operating room participants must give their consent to being recorded and monitored. Grantcharov says, "Someday, this will be a standard part of an operating room much like a black box is in an airplane today." donalee Moulton, Halifax, NS

CMAJ 2015. DOI:10.1503/cmaj.109-5071 